\title{
Correction to: ZEB1-AS1 initiates a miRNA-mediated ceRNA network to facilitate gastric cancer progression
}

Ming-Hui Ma', Jia-Xiang An ${ }^{1}$, Cheng Zhang ${ }^{1}$, Jie Liu² ${ }^{2}$ Yu Liang ${ }^{1}$, Chun-Dong Zhang ${ }^{1}$, Zhen Zhang ${ }^{1}$ and Dong-Qiu Dai ${ }^{1 *}$

\section{Correction to: Cancer Cell Int (2019) 19:27} https://doi.org/10.1186/s12935-019-0742-0

After publication of the original article [1], the authors have notified us of 5 errors which are highlighted below. The authors apologize for any inconvenience.

1. "ca-199 (tissue) (U/mL)" in Table 1 was incorrectly presented and should be replaced with "ca-199 (serum) $(\mathrm{U} / \mathrm{mL})$.
2. "miR-143-3p" in Table 2 was a mistake in spelling and should be replaced with "miR-149-3p".

3. We have corrected the $48 \mathrm{~h}$ representation in Fig. 5.

4. We have corrected the cell migration vector representation and the cell invasion LV-Z+miR-149-3p representation in Fig. 8.

5. The primer sequences with red color were out-oforder for the wrong type setting of Microsoft Word. Accordingly, we corrected it.

\footnotetext{
*Correspondence: daidq63@163.com

1 Department of Gastroenterological Surgery, The Fourth Affiliated

Hospital of China Medical University, Shenyang 110032, China

Full list of author information is available at the end of the article
} 

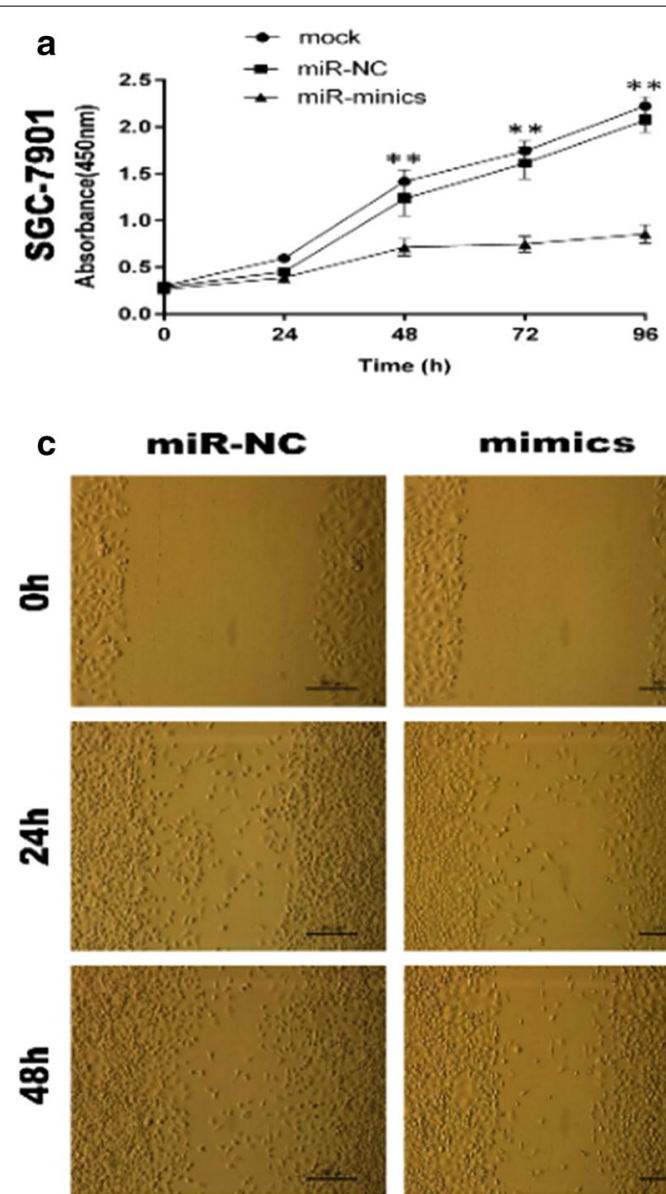

SGC-7901

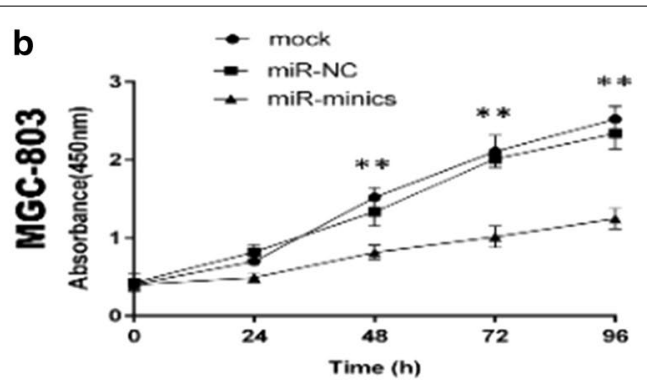

d
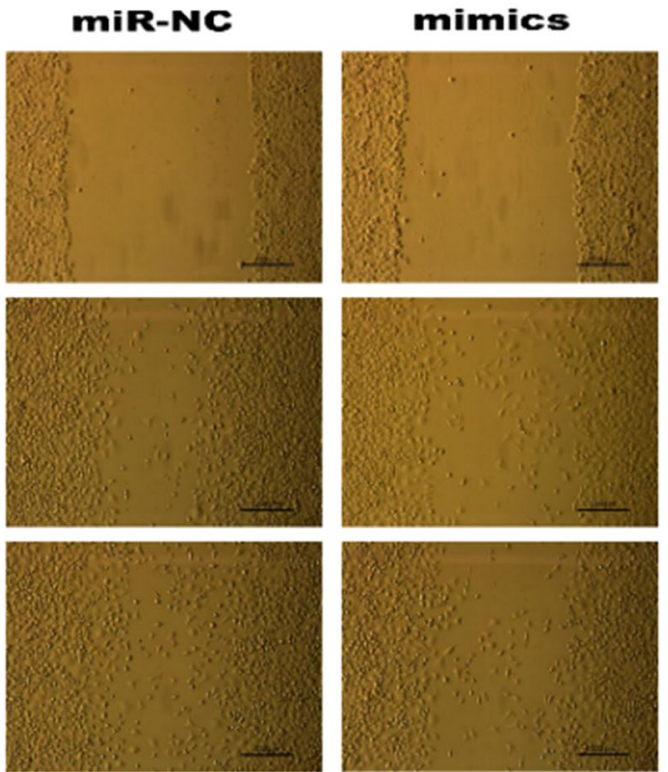

MGC-803

Fig. 5 MiR-149-3p suppressed GC cell proliferation and migration. $\mathbf{a}$, b The CCK-8 assays were performed in SGC-7901 and MGC-803 cells transfected with mimics or miR-NC (Two-way ANOVA). c, d The wound healing assays were performed in SGC-7901 and MGC-803 cells transfected with mimics or miR-NC. Mimics: 149-3p mimics; miR-NC: miR-149-3p negative control. ${ }^{*} \mathrm{P}<0.05$; ${ }^{* *} \mathrm{P}<0.01$ 

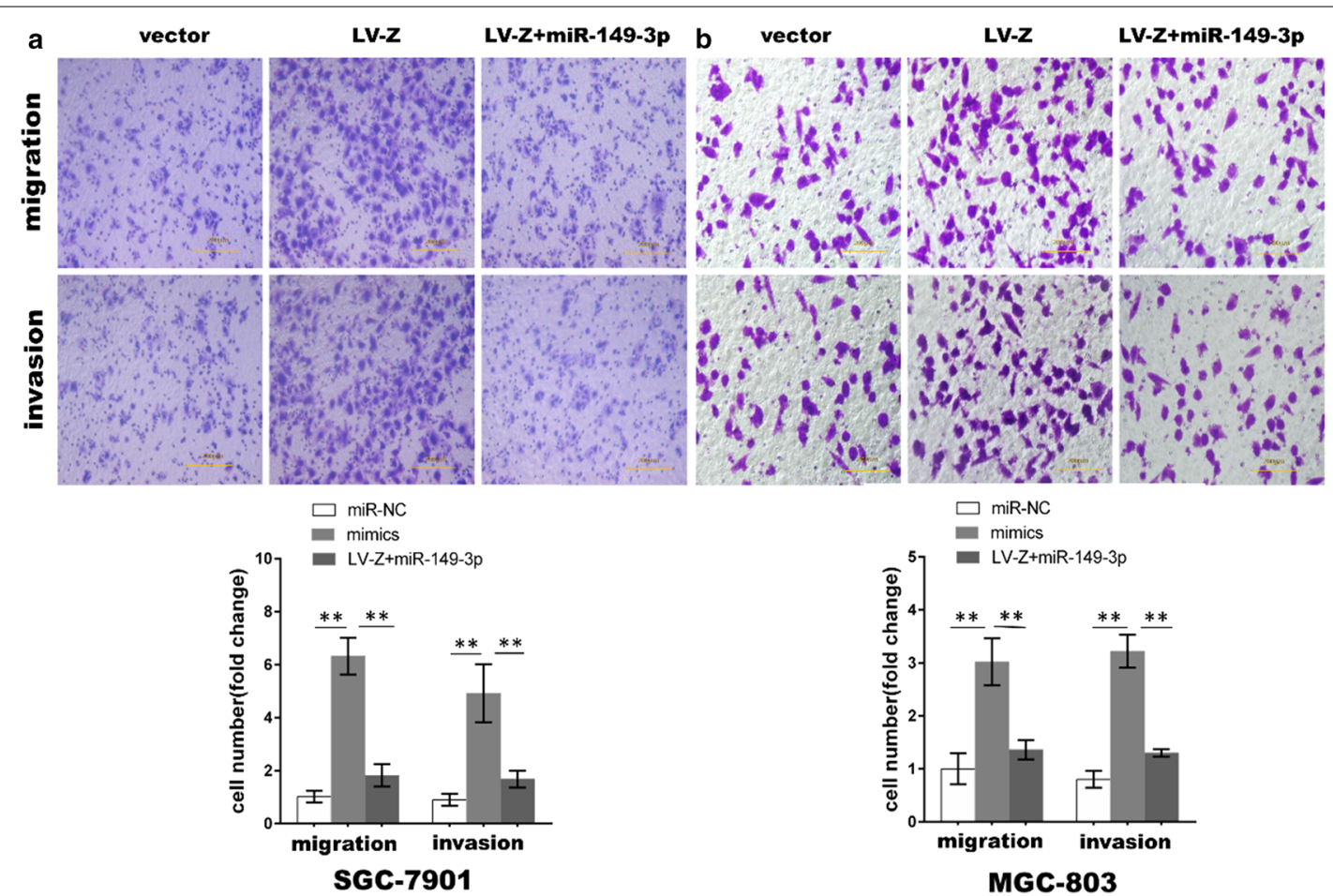

Fig. 8 MiR-149-3p partially abolished GC cell migration and invasion induced by ZEB1-AS1. a, b ZEB1-AS1-induced cell migration and invasion were partly abrogated by miR-149-3p (Two-way ANOVA). ${ }^{* P}<0.05 ;{ }^{* * P}<0.01$

\section{Additional file}

Additional file 2: Table S1. The sequence information involved in the study (Wrong). The sequence information involved in the study (Revised).

\section{Publisher's Note}

Springer Nature remains neutral with regard to jurisdictional claims in published maps and institutional affiliations.

Received: 22 March 2019 Accepted: 22 March 2019

Published online: 11 April 2019

\section{Reference}

1. Ma M-H, An J-X, Zhang C, Liu J, Liang Y, Zhang C-D, Zhang Z, Dai D-Q. ZEB1-AS1 initiates a miRNA-mediated ceRNA network to facilitate gastric cancer progression. Cancer Cell Int. 2019;19:27. https://doi.org/10.1186/ s12935-019-0742-0. 